\title{
Influence of Some Abiotic Risk Factors on Parental Forms in Some Registered Corn Hybrids (Zea mays, L)
}

\author{
Claudiu Gabriel BĂLAŞ-BACONSCHI ${ }^{1 *}$, Ioan HAŞ⿻ి,2, Ana COPÂNDEAN ${ }^{2}$ \\ $1^{1 *}$ University of Agricultural Sciences and Veterinary Medicine Cluj-Napoca, Calea Mănăştur 3-5, \\ 400372, Cluj-Napoca, Cluj, Romania \\ ${ }^{2}$ Agricultural Research and Development Station Turda, Str. Agriculturii nr. 27, Turda, Cluj, Romania \\ *Corresponding author: gabriel_balas@yahoo.com
}

Bulletin USAMV series Agriculture 72(2)/2015

Print ISSN 1843-5246; Electronic ISSN 1843-5386

DOI 10.15835/buasvmcn-agr: 11514

\begin{abstract}
Corn is one of the most important crops, and yield may be affected by risks that manifest more strongly in recent years. In hybrid seed production activity, these risks are even greater importance for breeder and for hybrid seed multiplier. Considering the risks mentioned, the objectives are to test the reaction of certain genotypes in different phenophases with manifestation of abiotic factors (low temperatures and hail). Genotypes analyzed were parental forms of hybrids homologated by ARDS Turda, and inbred lines used in the creation of hybrids. The analyzed risk factors were frost in phenophases of 5-6 leaves and 7-8 leaves, and we simulated a soft hail in 8-10 leaves and after pollination, an average hail, a "defoliation" of 50\% of the leaves and "defoliation" of $80-90 \%$ of the leaves. The effect of frost was almost insignificant in first phenophase, yield losses to $8 \%$ in hybrids, and $12 \%$ in inbred lines. In the second phenological phase, low temperatures losses of 51\% in hybrids, and $70 \%$ in inbred lines. Hail causes insignificant losses before pollination of $1 \%$ in hybrids and $0.5 \%$ in inbred lines. Instead total defoliation of hail, produce $71 \%$ losses in hybrids, and $70 \%$ in inbred lines. If the phenomena occurring in the later phenophases, both hybrids and inbred lines respond negatively in terms of yield, thousand grain weight, and corn cob yield. For inbred lines, negative temperatures have a stronger effect compared to hail. For both hybrids and inbred lines, hail caused a greater damage compared with frost.
\end{abstract}

Keywords: frost, hail, hybrids, inbred lines, Zea mays.

\section{INTRODUCTION}

Corn is one of the most important crops worldwide and like other crops, the yield can be affected by risks which have been more and more severe in the recent years. In the activity of production of hybrid seed, either research stations, trading companies or other multipliers, these risks are of greater importance. On one side, there is the possibility of decreasing the yields obtained on the surface units due to the occurrence of risk factors, and on the other hand, there is the danger to lose valuable genotypes by the apparition of destructive phenomena.

Research on risk factors were made by Coulter et al., (2011), Cristea et al., (2004, 2013), Dwyer et al., (1994), Egharevba et al., (1976), Klein et al., (2011), Petcu et al., (2007), Robertson et al., (2011).

Of tropical origin, corn is included in the group of thermophilic plants, sensitive to low temperatures. Spring temperatures are the most dangerous for corn. Adaptation to these conditions is explained by the temporization of the use of the reserve substances from the seed, moderate raising of the aerial part, the accumulation of the reserve substances in the young leaves as shown by Cristea et al., (2004).

Under the influence of low temperatures, the concentration of cell sap decreases, as this is a feature of the corn forms which are not cold resistant, in the strong parental forms, this decrease is lower. Knowing the capacity of chill resistance, 
it presents a particular importance both from the point of view of the stability of the optimal time for sowing, and of the microzoning works.

A severe loss of $50 \%$ has decreased the yield, due to a small number of grains on the cob. The decrease of the yield decreases with the minor loss of the leaves, according to Egharevba et al., (1976).

The decrease in dry substance and grains yield due to hail is correlated with the temperature indexes needed for each genotype to reach maturity. For the situations when the hail occurs in the stage of wax-milk, the hybrids with delayed maturity are the most affected by hail, as shown by Dwyer et al., (1994).

Corn retains the ability to compensate for lost plants through the late vegetative stages, indicating that current standards for assessing the effect of stand loss in corn should be re-evaluated according to Coulter et al., (2011).

In Romania, in recent years, the frequency of the damage caused by hail, storm, torrential rain or even the apparition of tornadoes, especially after 2000 according to Groupama Asigurări (2012). The affected corn surface and the number of events with losses in 2012 for Groupama Asigurări, is the following:

- corn for consumption 10.845,23 ha; number of events 12;

-hybrid lots 2.548,50 ha; number of events 39.

In 2013 and 2014 however, there was a smaller number of losses for the corn crop. Therefore, most events occurred in June 2013, and July 2014, and the event which caused the most damages was hail, as reported by Groupama Asigurări, (2012, 2013, 2014); (Tab.1).

From the research done, very few authors studied this field, most of them abroad. There were no studies regarding the hail effect in Romania, however studies were identified regarding the effect of negative temperatures on corn.

The goals of the study were:

- Knowing the resistance to low temperatures, the different simple hybrids, maternal and paternal parental forms of registered hybrids (Turda 201, Turda Star, Turda 200);

- Establishing the effect of low temperatures on seedlings with certain inbred lines of corn, parental forms of certain three-line registered hybrids (Turda 201, Turda 165);

- Determining the reaction of certain genotypes (simple hybrids and inbred lines) regarding the effect of the hail simulation in different vegetation stages.

\section{MATERIAL AND METHOD}

The biological material used in the researches was represented by:

-simple hybrids (2) parental maternal androsterile forms of the three-line hybrids Turda 201 and Turda Star;

-simple hybrid (1) maternal form of the double hybrid Turda 200;

-simple hybrid (1) paternal form of the double hybrid Turda 200;

-inbred lines (5) parental maternal and paternal forms of the hybrids Turda 248, Turda 332, Turda 201 and Turda Star.

Primary data come from 4 experiences, disposed in randomized blocks, 3 repeated, sowing density 70000 plants/ha.

The effect of low temperatures was studied in 2 experiences, with two graduations:

Factor A - simple hybrids and inbred lines (6)

Factor B - natural phenomena (3) by simulating a frost in the stage of 5-6 leaves and 7-8 leaves

Tab. 1 Frequency of losses per calendar months and risks in 2013 and 2014

\begin{tabular}{ccccccccc}
\hline Year & Risk occurred & May & June & July & August & September & October & Total \\
\hline \multirow{3}{*}{2013} & Hail & 1 & 35 & 15 & 8 & 3 & 1 & 63 \\
\cline { 2 - 10 } & Storm & 3 & 18 & 7 & 3 & 2 & 4 & 37 \\
\cline { 2 - 10 } & Torrential rain & 1 & 4 & 5 & 2 & 3 & 1 & 16 \\
\hline \multirow{3}{*}{2014} & Total & 5 & 57 & 27 & 13 & 8 & 6 & 116 \\
\cline { 2 - 9 } & Hail & 9 & 14 & 57 & 3 & & & 83 \\
\cline { 2 - 9 } & Storm & & 9 & 3 & & & 1 & 13 \\
\cline { 2 - 9 } & Torrential rain & 5 & 9 & 5 & 1 & 1 & 1 & 117 \\
\hline
\end{tabular}


(cutting the plants at the soil level) in relation with the Control sample (1)

The effect of hail was studied in two experiences, with 5 graduations:

Factor A - simple hybrids and inbred lines (6)

Factor B - natural phenomena (5) 1 Control; 2 soft hail in the stage of 8-10 leaves; 3 hail of average intensity, after the pollination; 4 exfoliation of a percent of $50 \%$ from the leaves after the pollination; 5 exfoliation of a percent of $80-90 \%$ from the leaves after the pollination.

For each of the studied genotypes there were observations regarding the date of the stigmata with the maternal forms and blooming with the paternal forms.

The observations and determinations in the case of the experimental system was done with plants and cobs, determining the production of grains (kg/ha), humidity and dry matter of the grains at the harvesting time, the erect plants at the harvesting time (\%).

\section{RESULTS AND DISCUSSIONS}

In terms of the simulation of low temperatures and hail in general, but also in terms of differentiating of the studied genotypes, the data obtained after the first year of experimenting were conclusive.

The genotypes reacted differently from the point of view of the yield, humidity and breaking resistance (Tab. 2, and Tab. 3).

For hybrids, the hybrid HS "M" cms Turda 201 recorded a yield of $12903 \mathrm{~kg}$. In the case of simulation of the first frost, the yield increased to 13518 kilograms, and for the second frost, the yield decreased to 8511 kilograms, representing 66\%

Tab. 2. Reaction of hybrids in case of low temperatures

\begin{tabular}{|c|c|c|c|c|c|}
\hline Hybrid & Graduation & $\begin{array}{l}\text { Grains } \\
\text { yield }\end{array}$ & & $\begin{array}{c}\text { Dry } \\
\text { matter }\end{array}$ & $\begin{array}{c}\text { Plant not } \\
\text { broken }\end{array}$ \\
\hline & & (kg/ha) & $(\%)$ & & \\
\hline HS „M“ cms Turda 201 & Control & 12903 & 100.0 & 80.6 & 82.7 \\
\hline $\mathrm{HS}$ „M“ cms Turda 201 & simulation low temperatures (5-6 leaves) & 13518 & 104.8 & 80.6 & 90.2 \\
\hline HS „M“ cms Turda 201 & simulation low temperatures (7-8 leaves) & 8511 & 66.0 & 78.5 & 95.8 \\
\hline $\mathrm{HS}$ „,M“ cms Turda Star & Control & 13823 & 100.0 & 78.9 & 95.5 \\
\hline HS „,M“ cms Turda Star & simulation low temperatures (5-6 leaves) & 12979 & 93.9 & 78.4 & 89.8 \\
\hline $\mathrm{HS}$ „,M“ cms Turda Star & simulation low temperatures (7-8 leaves) & 8028 & 58.1 & 76.2 & 89.4 \\
\hline HS „T" Turda 200 & Control & 13456 & 100.0 & 81.4 & 52.6 \\
\hline HS „T" Turda 200 & simulation low temperatures (5-6 leaves) & 10490 & 78.0 & 81.7 & 46.3 \\
\hline $\mathrm{HS}$ „T" Turda 200 & simulation low temperatures (7-8 leaves) & 3375 & 25.1 & 80.7 & 71.0 \\
\hline
\end{tabular}

Tab. 3. Reaction of inbred lines in case of low temperatures

\begin{tabular}{cccccc}
\hline Inbred line & Graduation & $\begin{array}{c}\text { The yield } \\
\text { of grains }\end{array}$ & \multicolumn{2}{c}{$\begin{array}{c}\text { Dry matter } \\
(\%)\end{array}$} & $\begin{array}{c}\text { Plants not } \\
\text { broken } \\
(\%)\end{array}$ \\
\hline LC 660 & Control & 6861 & 100.0 & 78.6 & 78.1 \\
\hline LC 660 & simulation low temperatures (5-6 leaves) & 5080 & 74.0 & 79.9 & 84.6 \\
\hline LC 660 & simulation low temperatures (7-8 leaves) & 857 & 12.5 & 79.5 & 78.5 \\
\hline LC 733 & Control & 5095 & 100.0 & 83.3 & 79.3 \\
\hline LC 733 & simulation low temperatures (5-6 leaves) & 4733 & 92.9 & 83.8 & 84.8 \\
\hline LC 733 & simulation low temperatures (7-8 leaves) & 1645 & 32.3 & 82.9 & 84.7 \\
\hline LC 761 cms „C“ & Control & 7455 & 100.0 & 80.7 & 97.3 \\
\hline LC 761 cms „C“ & simulation low temperatures (5-6 leaves) & 7332 & 98.4 & 80.4 & 99.3 \\
\hline LC 761 cms „C“ & simulation low temperatures (7-8 leaves) & 3258 & 43.7 & 80.1 & 95.9 \\
\hline
\end{tabular}


compared to the Control. The hybrid HS"M"cms Turda Star reacted better, as a Control with a yield of $13823 \mathrm{~kg}$, in the case of the first frost the yield decreased to $12979 \mathrm{~kg}$, and for the second frost, the yield decreased to $8028 \mathrm{~kg}$, representing $58 \%$ din the yield recorded by the Control. The simple hybrid "T"Turda 200 was the most affected, compared to the Control where a yield of $13456 \mathrm{~kg}$ was recorded, the first frost produced a decrease of the yield to $10490 \mathrm{~kg}$, that is $77 \%$ of the potential, and the second frost produced a decrease of the yield to $3375 \mathrm{~kg}$, representing $25 \%$ from the potential. The hybrid HS"M" cms Turda 201 proved the best resistance to negative temperatures.

Inbred lines reacted to negative temperatures differently. The line 660 recorded a yield of 6861 kilograms in the case of the Control, of $5080 \mathrm{~kg}$ in the case of the first frost, and $857 \mathrm{~kg}$ in the case of the second frost, that is $12 \%$ from the potential.

The line LC 733 recorded a yield of 5095 in the case of the Control, a yield of $4733 \mathrm{~kg}$ in the case of the first frost, and $1645 \mathrm{~kg}$ in the case of the second frost, that is $32 \%$ from the potential. The line LC $761 \mathrm{cms} C$ recorded a yield of $7455 \mathrm{~kg}$ in the case of the Control, a yield of $7332 \mathrm{~kg}$ for the first frost, and 3258 kilograms for the second frost, that is $44 \%$ from the potential. From the inbred lines, the line LC $761 \mathrm{cms} \mathrm{C}$ was the most resistant to this phenomenon.

For the hail risk, the results obtained for the simple hybrids and inbred lines are described in Tab 4 and Tab 5.

The hybrid HS "M" cms C Turda 201 recorded a yield of $12791 \mathrm{~kg}$, and the first phenomenon of hail simulation has lead to a degrease of the yield by 786 kilograms. The second factor has determined a decrease of the yield up to 11347 kilograms. The third factor has decreased the yield to 9098 kilograms, and the fourth phenomenon has decreased the yield to 3760 kilograms, representing 29\% from the production potential.

The hybrid HS "M" cms Turda Star recorded a yield of $13956 \mathrm{~kg}$ ca Control, and the first phenomenon of hail simulation of hail has lead to a decrease of the yield cu 671 kilograms. The second factor has caused a new decrease of the yield up to 13183 kilograms.

The third factor has decreased the yield to 9764 kilograms, and the fourth phenomenon has decreased the yield to 3375 kilograms, representing $24 \%$ from the potential. The hybrid HS "T" Turda 200 has recorded a yield of 11549 $\mathrm{kg}$ to the Control, and the first phenomenon of hail simulation has lead to a increase of the hail has lead to an increase of the yield to 12186

Tab. 4. Reaction of hybrids in case of simulated hail

\begin{tabular}{|c|c|c|c|c|c|}
\hline The hybrid & Graduation & $\begin{array}{l}\text { The yield } \\
\text { of grains } \\
\text { (kg/ha) }\end{array}$ & $(\%)$ & $\begin{array}{c}\text { Dry } \\
\text { matter } \\
(\%)\end{array}$ & $\begin{array}{c}\text { Plants not } \\
\text { broken } \\
(\%)\end{array}$ \\
\hline HS „M“ cms Turda 201 & Control & 12791 & 100.0 & 80.3 & 78.6 \\
\hline HS „M“ cms Turda 201 & soft hail in the stage of (7-8 leaves) & 12005 & 93.9 & 80.3 & 87.1 \\
\hline HS „M“ cms Turda 201 & average hail after pollination & 11347 & 88.7 & 80.6 & 78.6 \\
\hline HS „M“ cms Turda 201 & exfoliation $50 \%$ after pollination & 9098 & 71.1 & 80.2 & 85.1 \\
\hline HS „M“ cms Turda 201 & exfoliation $80-90 \%$ after pollination & 3760 & 29.4 & 81.3 & 15.8 \\
\hline HS „M“ cms Turda Star & Control & 13956 & 100.0 & 78.3 & 83.3 \\
\hline HS „M“ cms Turda Star & soft hail in the stage of (7-8 leaves) & 13854 & 99.3 & 78.2 & 85.1 \\
\hline HS „M“ cms Turda Star & average hail after pollination & 13183 & 94.5 & 79.1 & 79.5 \\
\hline HS „M“ cms Turda Star & exfoliation $50 \%$ after pollination & 9764 & 70.0 & 78.3 & 58.7 \\
\hline HS „M“ cms Turda Star & exfoliation $80-90 \%$ after pollination & 3375 & 24.2 & 81.6 & 7.1 \\
\hline HS “T” Turda 200 & Control & 11549 & 100.0 & 80.4 & 73.1 \\
\hline HS “T” Turda 200 & soft hail in the stage of (7-8 leaves) & 12186 & 105.5 & 80.3 & 78.1 \\
\hline HS “T” Turda 200 & average hail after pollination & 10175 & 88.1 & 80.8 & 72.7 \\
\hline HS “T” Turda 200 & exfoliation $50 \%$ after pollination & 9040 & 78.3 & 80.3 & 62.9 \\
\hline HS “T” Turda 200 & exfoliation $80-90 \%$ after pollination & 3582 & 31.0 & 79.1 & 29.8 \\
\hline
\end{tabular}


kilograms. The second phenomenon has caused a decrease of the yield up to 10175 kilograms. The third phenomenon has decreased the yield to 9040 kilograms, and the fourth phenomenon has decreased the yield to 3582 kilograms, representing $31 \%$ from the potential.

In the case of the inbred lines, the line LC A Turda 248 has recorded a yield of 5794 kilograms. The first phenomenon has decreased the yield to 5886 kilograms, the second phenomenon to 5623 kilograms, the third phenomenon to 4695 kilograms, and the fourth phenomenon to the yield de 2619 kilograms representing 45\% compared to the Control. The line LC „A“ Turda 332 has recorded a yield of 9672 kilograms in the case of the Control. The first phenomenon has decreased the yield to 9425 kilograms, the second to $8341 \mathrm{~kg}$, the third to $8219 \mathrm{~kg}$, and the fourth to 1788 kilograms, representing $18 \%$ as compared to the potential. The line $\mathrm{LC} 761 \mathrm{cms} \mathrm{C}$ recorded a yield of 7080 kilograms as a Control. The first phenomenon did not affect the product capacity of $7151 \mathrm{~kg}$, the second of $7044 \mathrm{~kg}$, the third of 5796 $\mathrm{kg}$, and the fourth of 2054 kilograms, representing $29 \%$ compared to the Control.

The breaking resistance. The poorest resistance to breaking has been recorded for the hybrids HS "M" cms Turda Star and HS "M" cms Turda 201 in the simulation of hail with exfoliation de $80-90 \%$ after pollination. Inbred lines have proved a better resistance to breaking, the poorest resistance being recorded by the corn inbred lines LC $761 \mathrm{cms}$ "C" and LC „A“ Turda 332 in simulating the hail with exfoliation of $80-90 \%$ after pollination. From the point of view of the dry matter accumulation, the analyzed genotypes have not presented important decreases in accumulating dry matter.

Physiological maturity. In the case of simulation of low temperatures, the hybrid HS „M" cms Turda 201 has recoreded a longer number of days for maturity, both for the first and for the second phenomenon of frost simulation.

The hybrid HS "M" cms Turda Star has recorded, compared to the Control a number of 6 days more for the first simulation, respectively 3 days for the second simulation of the frost (7-8 leaves).

The hybrid HS "T" Turda 200 has recorded up to maturity the same number of days as the Control, and for the second simulation it has recorded a maturity delay of 11 days.

For the inbred lines, the line LC 660, in simulating the second phenomenon, was more affected, the plants being abnormally developed, as they have not reached maturity.

Tab 5 Reaction of hybrids in case of simulated hail

\begin{tabular}{|c|c|c|c|c|c|}
\hline The inbred line & Graduation & $\begin{array}{l}\text { The yield } \\
\text { of grains }\end{array}$ & $(\%)$ & $\begin{array}{c}\text { Dry } \\
\text { matter } \\
(\%)\end{array}$ & $\begin{array}{c}\text { Plants not } \\
\text { broken } \\
(\%)\end{array}$ \\
\hline LC “A” Turda 248 & Control & 5794 & 100 & 79.0 & 97.9 \\
\hline LC" A" Turda 248 & soft hail in the stage of (7-8 leaves) & 5886 & 101.6 & 79.4 & 92.7 \\
\hline LC" A" Turda 248 & average hail after pollination & 5623 & 97.0 & 79.7 & 94.8 \\
\hline LC" A" Turda 248 & exfoliation $50 \%$ after pollination & 4695 & 81.0 & 81.6 & 79.0 \\
\hline LC" A" Turda 248 & exfoliation $80-90 \%$ after pollination & 2619 & 45.2 & 82.3 & 61.6 \\
\hline LC „A“ Turda 332 & Control & 9672 & 100 & 77.7 & 98.1 \\
\hline LC „A“ Turda 332 & soft hail in the stage of (7-8 leaves) & 9425 & 97.4 & 78.6 & 97.4 \\
\hline LC „A“ Turda 332 & average hail after pollination & 8341 & 86.2 & 78.9 & 96.7 \\
\hline LC „A“ Turda 332 & exfoliation $50 \%$ after pollination & 8219 & 85.0 & 79.3 & 98.7 \\
\hline LC „A“ Turda 332 & exfoliation $80-90 \%$ after pollination & 1788 & 18.5 & 82.1 & 57.2 \\
\hline LC $761 \mathrm{cms}$ "C" & Control & 7080 & 100 & 80.8 & 97.4 \\
\hline LC $761 \mathrm{cms}$ "C" & Soft hail in the stage (de 7-8 leaves) & 7151 & 101.0 & 80.6 & 96.6 \\
\hline LC $761 \mathrm{cms}$ "C" & average hail after pollination & 7044 & 99.5 & 81.2 & 89.6 \\
\hline LC $761 \mathrm{cms}$ “C” & exfoliation $50 \%$ after pollination & 5796 & 81.9 & 82.8 & 87.1 \\
\hline LC $761 \mathrm{cms}$ "C" & exfoliation $80-90 \%$ after pollination & 2054 & 29.0 & 82.0 & 22.9 \\
\hline
\end{tabular}


For the lines LC 733 si LC $761 \mathrm{cms}$ "C", in simulating the low temperatures in the stage of 7-8 leaves a delay of the physiological maturity was recorded by 6 respectively 8 days as compared to the Control. In simulating the hail, for the hybrid HS "M" Turda 201, the simulation of the hail after pollination determined a maturity by 7 days earlier as compared to the Control.

The hybrid HS "M" cms Turda Star the physiological maturity for the hail simulation after pollination has determined a forced maturity by 12 days earlier as compared to the Control, and the hybrid HS "T" Turda 200, the physiological maturity was recorded 9 days earlier as compared to the Control.

In the case of inbred lines, in simulating the hail after pollination, a forced maturity was achieved, by 9 respectively 13 days as compared to the Control, for the lines LC $761 \mathrm{cms} \mathrm{C}$, and LCA Turda 248, only the line LC A Turda 332 was more stable from the point of view of the number of days needed to reach physiological maturity.

\section{CONCLUSIONS}

From the point of view of the simulation of the resistance to low temperatures, hybrids proved a better resistance and a better capacity of yield as compared to inbred lines.

Among the hybrids, the best yields have been recorded by the hybrid HS "M" cms Turda Star, but from the point of view of the hail resistance, the most resistant was the hybrid HS "T" Turda 200 , which was positively influenced by the hail simulation in the phase of 8-10 leaves.

Among the analyzed inbred lines, the line LC "A" Turda 332 was the most productive, but the most resistant to this phenomenon proved to be the line LCA Turda 248.

Comparing the reaction of the hybrids with the inbred lines, hybrids prove a better resistance to the hail risk as compared to the inbred lines.

The effect of the frost was insignificant in the case of the first stage (5-6 leaves), the yield losses being $8 \%$ in the case of hybrids, and $12 \%$ in the case of inbred lines.

In the stage of 7-8 leaves, the simulation of low temperatures has determined losses of $51 \%$ in the case of hybrids and $70 \%$ in the case of inbred lines.

Hail causes insignificant loses before pollination, $1 \%$ in the case of hybrids and $0.5 \%$ in the case of inbred lines.
Hail with exfoliation of $80-90 \%$ causes losses of $71 \%$ in the case of hybrids and $70 \%$ in the case of inbred lines. Corn succeeds to obtain yields even under maximum stress conditions, and in the case of apparition of negative temperatures or hail phenomena during the early stages.

Testing the resistance to falling proved that the plants where exfoliation is total after hail phenomena, have a very low resistance to breaking, as the plants fail to support by themselves when facing stronger winds.

\section{RECOMMENDATION}

Avoiding or preventing the risk consists in taking measures in order to decrease them to minimum, such as:

Surveying the areas where the risk factors and microzoning or placing the strategic crops on different parcels, at a distance from each others, especially for the parental forms which will be the basis to create hybrids;

Abandoning the cropping in certain areas of those genotypes which are particularly sensitive to hail or low temperatures, corroborated with the selection of a variety of stronger plants;

Creating hybrids resistant to abiotic limitative environment factors.

\section{REFERENCES}

1. Cristea M, Cabulea I, Sarca T (2004). Porumbul, Studiu Monografic, Vol 1, Editura Academiei Române, 129-135

2. Cristea M (2013). Rezistenta porumului la frig, ANSEM, 8: 10-12.

3. Coulter JA, Nafziger ED, Abendroth LJ, Thomison PR, Elmore RW and Zarnstorff ME, 2011, Agronomic Responses of Corn to Stand Reduction at Vegetative Growth Stages, Agronomy Journal, 103(3): 577-583.

4. Dwyer LM, Tewart DW, Evenson L and Ma BL (1994). Maize Growth and Yield Following Late Summer Hail, Crop Science, vol 34, 1400-1403

5. Egharevba PN, Horrocks RD, Zuber MS (1976). Dry Matter Accumulation in Maize in Response to Defoliation, Agronomy Journal, 68: 40-43.

6. Groupama Asigurări (2012). Analize daune asigurari agricole, raport annual.

7. Groupama Asigurări (2013). Analize daune asigurari agricole, raport annual.

8. Groupama Asigurări (2014). Analize daune asigurari agricole, raport annual.

9. Klein RN, Saphiro CA (2011). Evaluating Hail Damage to Corn, University of Nebraska Lincoln Extension, The Board of Regents

10. Petcu E, Țerbea M, Lazăr C (2007). Rezistenta la temperaturi scazute, Volum Omagial I.N.C.D.A. Fundulea, LXXV: 432-434.

11. Robertson AE, Munkwold GP, Hurburg CR, Ensley S (2011). Effects of Natural Hail Damage on Ear Rots, Mycotoxins, and Grain Quality Characteristics of Corn 